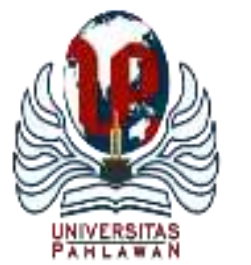

Edukatif : Jurnal Ilmu Pendidikan Volume 3 Nomor 6 Tahun 2021 Halm 4683 - 4688

EDUKATIF: JURNAL ILMU PENDIDIKAN

Research \& Learning in Education

https:/ledukatif.org/index.php/edukatif/index

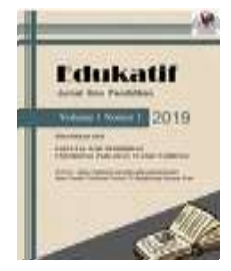

\title{
Penerapan Pendidikan Kewarganegaraan sebagai Penguat Sikap Bela Negara Bagi Siswa Sekolah Dasar
}

\author{
Dini Anggraeni Dewi ${ }^{1 凶}$, Yayang Furi Furnamasari², Angel Dwi Septiaingrum ${ }^{3}$, \\ Vioreza Dwi Yunianti ${ }^{4}$ \\ Universitas Pendidikan Indonesia, Indonesia ${ }^{1,2,3,4}$ \\ E-mail : $\underline{\text { diniangraenidewi@upi.edu }}^{1}, \underline{\text { uri2810@upi.edu }}^{2},{\underline{\text { angelds@ } @ u^{2} i . e d u}}^{3}, \underline{v i o z d w y n 23 @ u p i . e d u}^{4}$
}

\begin{abstract}
Abstrak
Indonesia merupakan sebuah negara yang masih rentan akan adanya konflik akibat perbedaan. Dimana dalam mengatasi hal ini, maka setiap warga negaranya haruslah mengerti mengenai fungsi sebagai warga negara termasuk mengerti upaya bela negara yang harus dimiliki. Hal ini dapat diwujudkan sedini mungkin melalui Pendidikan Kewarganegaraan melalui sektor pendidikan formal. Artikel ini bertujuan untuk mempelajari bagaimana Pendidikan Kewarganegaraan yang diterapkan di lingkungan sekolah dasar dapat menumbuhkan sikap bela negara bagi peserta didik. Penelitian ini menggunakan metode kualitatif dan pendekatan deskriptif analitik untuk membahas permasalahan yang ada. Data sekunder didapatkan dari sumber buku, jurnal, dan juga situs online resmi yang kemudian disajikan untuk menunjang analisis. Hasil penelitian menunjukkan bahwa pada dasarnya Pendidikan Kewarganegaraan memiliki kompetensi dan kurikulum dalam bentuk tujuan yang harus dipenuhi yaitu untuk menumbuhkan rasa nasionalisme, pemahaman mengenai hak dan kewajiban warga negara, nilai dan moral, serta upaya implementasi bela negara itu sendiri. Upaya bela negara yang termasuk kedalam karakter nasionalisme dapat dipupuk dan diajarkan kepada siswa sekolah dasar dengan cara baik kognitif melalui pembelajaran di kelas, afektif dengan mengajarkan dan mencontohkan, maupun gabungan keduanya dengan membuat pembelajaran kreatif dan menyenangkan.
\end{abstract}

Kata Kunci: Bela negara, pendidikan karakter, Pendidikan Kewarganegaraan, sekolah dasar.

\begin{abstract}
Indonesia is a country that is still vulnerable to conflicts due to differences. In overcoming this, every citizen must understand the function as a citizen, including understanding the efforts to defend the country that must be owned. This can be realized as early as possible through Citizenship Education through the formal education sector. This article aims to study how Citizenship Education implemented in elementary schools can foster an attitude of defending the country for students. This study uses qualitative methods and analytical descriptive approaches to discuss the existing problems. Secondary data is obtained from sources of books, journals, and also official online sites which are then presented to support the analysis. The results of the study show that basically, Citizenship Education has competencies and curriculum in the form of goals that must be met, namely to foster a sense of nationalism, an understanding of the rights and obligations of citizens, values, and morals, as well as efforts to implement state defense itself. Efforts to defend the state which are included in the character of nationalism can be fostered and taught to elementary school students in a good way cognitive through classroom learning, affective by teaching and exemplifying, or a combination of both by making learning creative and fun.
\end{abstract}

Keywords: state defense, character education, Citizenship Education, elementary school

Copyright (c) 2021 Dini Angraeni Dewi, Yayang Furi, Angel Dwi Septiaingrum, Vioreza Dwi Yunianti

$\triangle$ Corresponding author:

Email : diniangraenidewi@upi.edu

DOI : $\quad$ https://doi.org/10.31004/edukatif.v3i6.1550

ISSN 2656-8063 (Media Cetak)

ISSN 2656-8071 (Media Online)

Edukatif : Jurnal Ilmu Pendidikan Vol 3 No 6 Tahun 2021 p-ISSN 2656-8063 e-ISSN 2656-8071 
4684 Penerapan Pendidikan Kewarganegaraan sebagai Penguat Sikap Bela Negara Bagi Siswa Sekolah Dasar - Dini Angraeni Dewi, Yayang Furi, Angel Dwi Septiaingrum, Vioreza Dwi Yunianti

DOI: https://doi.org/10.31004/edukatif.v3i6.1550

\section{PENDAHULUAN}

Indonesia merupakan sebuah bangsa yang memiliki heterogen dan plural dalam berbagai hal. Baik dari bahasa, budaya, tempat tinggal, etnis, bahkan hingga ciri dan karakteristik fisik yang dimiliki masyarakatnya. Sebagai bangsa yang heterogen seperti ini, maka tidak heran bahwa bentuk tantangan dan permasalahan dalam kehidupan berbangsa dan bernegara di Indonesia sering ditemukan. Menurut data dari Yayasan Denny JA yang berfokus dalam bidang politik sosial di Indonesia, masih terdapat banyak sekali kasus konflik dan diskriminasi yang berhubungan dengan pluralisme di Indonesia. Yaitu rata-rata sebanyak lebih dari 2 ribu kasus dengan persentase konflik agama sebesar $60 \%$, konflik etnis $20 \%$, konflik gender $10 \%$, dan konflik kategori lainnya sebesar 5\% (Rambey, 2020).

Dari jumlah tersebut, maka dapat dikatakan bahwa resiko disintegrasi dan permasalahan lainnya di Indonesia masih sangat mungkin terjadi. Untuk itu, guna mengatasi permasalahan yang berkaitan dengan pluralisme bangsa dan konflik perbedaan ini, maka nilai-nilai seperti nasionalisme, bela negara, dan juga penguatan karakter nasional perlu diajarkan bagi setiap masyarakat. Nasionalisme dan bela negara adalah dua hal yang berkaitan, yang apabila kedua hal ini dipelajari akan menimbulkan rasa cinta tanah air dan juga negara Indonesia bagi masyarakat.

Bentuk pengajaran nilai-nilai ini dapat dilakukan melalui sebuah metode pengajaran dan pendidikan, baik formal maupun non formal. Misalnya dengan melalui sebuah bentuk Pendidikan Kewarganegaraan. Pendidikan menurut (Sugihartono et al., 2013) merupakan sebuah proses pengalihan pengetahuan yang dilakukan secara sistematis dan terstruktur dari seseorang kepada orang lain dengan berpegang pada standar tertentu dan bertujuan untuk menanamkan ilmu. Tujuan untuk menanamkan ilmu ini dapat diupayakan dalam berbagai cara yang kemudian juga disesuaikan dengan kondisi pelaksanaan pendidikan yang ada. Pendidikan Kewarganegaraan adalah ilmu yang digunakan untuk menanamkan nilai-nilai kewarganegaraan sebagai warga negara termasuk bela negara dan dasar penguatan karakter (Magdalena et al., 2020). Untuk itu, penting bahwa pendidikan jenis ini diterapkan sedini mungkin.

Berbagai penelitian terdahulu telah banyak melakukan studi terhadap Pendidikan Kewarganegaraan di sekolah dasar baik dalam kurikulum, pelaksanaan, hingga implementasinya. Misalnya penelitian oleh (Nurdin, 2015) yang membahas dimensi penerapan Pendidikan Kewarganegaraan yang juga bersumber dari kebijakankebijakan yang diberlakukan. Penelitian ini membahas mengenai bagaimana Pendidikan Kewarganegaraan merupakan upaya penanaman nilai berbasis pendidikan yang menekankan pada perwujudan warga negara yang baik, yang memiliki kompetensi holistik dalam pengetahuan, keterampilan, dan sifat-sifat berdasarkan karakter bangsa. Dimana dalam upaya pendidikan ini, maka berbagai hasil dan nilai dapat didapatkan dan tertanam di diri peserta didik apabila dilakukan dengan cara yang tepat.

Penelitian selanjutnya oleh (Ulfa et al., 2020) mempelajari mengenai bagaimana pembentukan rasa nasionalisme dan bela negara dapat dilakukan dengan menanamkan Pendidikan Kewarganegaraan bagi siswa sekolah dasar. Pada penelitian ini dibahas mengenai skema yang perlu dilakukan agar mencapai tujuan yang diperlukan. Yaitu dengan memaksimalkan proses penanaman rasa nasionalisme dan bela negara pada silabus dan RPS; penggunaan ranah kognitif, afektif, dan psikomotor bagi siswa usia sekolah dasar; dan kemudian dengan berbagai cara dan inovasi pembelajaran yang menyenangkan bagi siswa.

Penelitian lainnya membahas dimensi Pendidikan Kewarganegaraan yang juga dapat diintegrasikan dengan pola pendidikan lainnya yaitu pendidikan karakter dengan tujuan untuk memupuk karakter baik pada peserta didik dan memperkuat karakter tersebut sebagai dasar upaya bela negara yang akan dilakukan (Kurniawan, 2013). Bentuk integrasi ini dapat dilakukan dengan melalui cara dan inovasi pembelajaran dokumentasi, pemahaman standar kompetensi, pemahaman komptenesi dasar, dan inovasi belajar lainnya. Penelitian ini menunjukkan hasil nilai karakter apa saja yang dapat diintegrasikan dengan Pendidikan 
4685 Penerapan Pendidikan Kewarganegaraan sebagai Penguat Sikap Bela Negara Bagi Siswa Sekolah Dasar - Dini Angraeni Dewi, Yayang Furi, Angel Dwi Septiaingrum, Vioreza Dwi Yunianti

DOI: https://doi.org/10.31004/edukatif.v3i6.1550

Kewarganegaraan. Diantaranya adalah karakter sosial, demokratis, nasionalisme, bela negara, disiplin, jujur, bertanggung jawab, semangat kebangsaan, toleransi, dan sebagainya.

Dari beberapa contoh penelitian mengenai pelaksanaan Pendidikan Kewarganegaraan di tingkat sekolah dasar ini, terdapat beberapa persamaan dimana dalam setiap penelitian penekanan yang dilakukan adalah dengan menerapkan pendidikan kewarganeragaan dengan peraturan dan kurikulum yang ada. Serta tujuan yang diinginkan pastinya harus memenuhi standar komptenesi yang diterapkan. Namun artikel ini selanjutnya akan membahas secara lebih mendalam mengenai bagaimana pelaksanaan Pendidikan Kewarganegaraan ini dapat mempengaruhi upaya bela negara yang dimiliki oleh siswa secara sistematis. Penelitian ini juga akan melakukan pertimbangan dengan penelitian-penelitian lain yang sudah ada sebagai bahan pendukung kepustakaan.

\section{METODE PENELITIAN}

Penelitian ini merupakan penelitian yang menggunakan metode kualitatif dan menekankan pada pendekatan deskriptif-analitik untuk menjelaskan dan sekaligus menganalisis permasalahan yang ada seperti yang dijelaskan pada bagian pendahuluan. Sejalan dengan pemikiran (Sugiono,2010) yang mengatakan bahwa kualitatif ialah metode dengan landasan filsafat positivme, pendekatan ini menggunakan metode kualitatif yang berfokus pada kajian pustaka atau literature review untuk mengumpulkan data, sumber dan bukti-bukti pendukung terkait dengan permasalahan yang dibahas. Data yang di eksplorasi merupakan data sekunder yang didapatkan melalui buku-buku referensi dan jurnal penelitian, berita online, situs online resmi, dan sebagainya yang kemudian dijadikan sebagai pendukung analisis. Referensi atau literature yang dipilih adalah buku-buku, jurnal, dan penelitian yang relevan dan berkaitan dengan penelitian mengenai Pendidikan Kewarganegaraan, bela negara, dan pendidikan sekolah dasar. Data yang telah dikumpulkan beserta sumber referensi yang relevan tersebut selanjutnya di analisis kemudian disajikan dan diambilnya kesimpulan setelah menghimpun data dan menganalisis secara terperinci serta tersusunnya kategori untuk mempurmudah penulis mengambil kesimpulan untuk menjawab pertanyaan dalam penelitian.

\section{HASIL DAN PEMBAHASAN PENELITIAN}

\section{Kompetensi dan Kurikulum Pendidikan Kewarganegaraan}

Pendidikan merupakan salah satu bidang yang memiliki keharusan dimana kebijakan ditentukan oleh pemerintah pusat untuk mengatur mengenai standar pendidikan meskipun kebijakan otonomi terkait pendidikan di tingkat daerah juga diperbolehkan. Dalam hal ini, Indonesia juga menggunakan cara serupa. Dimana standar pendidikan khususnya pendidikan sekolah dasar diatur secara nasional seperti misalnya standar kompetensi, kompetensi dasar, kurikulum, dan sebagainya. Pendidikan Kewarganegaraan juga memiliki standar kompetensi dan kurikulum yang diatur secara nasional oleh pemerintah pusat.

Kurikulum Pendidikan Kewarganegaraan di Indonesia merupakan kurikulum yang menekankan pada kompetensi yang dimiliki peserta didik secara holistic yang bertujuan untuk menyeimbangkan antara nilai dan moral, penerapan, serta fungsinya bagi kehidupan bermasyarakat (Iswandi, 2019). Selain itu menurut (Komara, 2017), kurikulum Pendidikan Kewarganegaraan di Indonesia berfokus pada meningkatkan literasi politik; menciptakan warga negara Indonesia yang cerdas dan terampil; memupuk kemampuan warga negara dalam aspek pengetahuan, keterampilan, maupun nilai dan sikap; mengidentifikasi masalah, dan mendorong peserta didik untuk memunculkan alternatif pemecahan masalah terkait kewarganegaraan.

PKn di Indonesia mencakup pembelajaran dalam hal domain sikap keagamaan dan sosial, pengetahuan dan kemampuan sebagai warga negara. Kemudian juga mempelajari hal lainnya seperti Pancasila, UndangUndang Dasar Negara Kesatuan Republik Indonesia 1945, Nilai dan semangat Bhinneka Tunggal Ika, dan Negara Kesatuan Republik Indonesia itu sendiri (Harmanto et al., 2017). Dimana dengan hal ini, maka tujuan dari Pendidikan Kewarganegaraan berfokus pada bagaimana agar praktik fungsi sebagai warga negara dapat 
4686 Penerapan Pendidikan Kewarganegaraan sebagai Penguat Sikap Bela Negara Bagi Siswa Sekolah Dasar - Dini Angraeni Dewi, Yayang Furi, Angel Dwi Septiaingrum, Vioreza Dwi Yunianti

DOI: https://doi.org/10.31004/edukatif.v3i6.1550

dijalankan dan ditanam dengan baik kepada peserta didik yang merupakan warga negara Indonesia. Namun sayangnya dalam aktualisasi di dunia nyata, masih saja terdapat berbagai permasalahan dalam pelaksanaannya. Seperti misalnya pengaruh politik yang sering dimasukkan kedalam upaya Pendidikan Kewarganegaraan, yang dimana hal ini adalah kondisi yang tidak pantas bagi siswa sekolah dasar yang belum tentu memahami benar apa konsep politik tersebut (Sunarso, 2018).

\section{Pendidikan Kewarganegaraan Sebagai Penguat Bela Negara}

Bela negara pada dasarnya adalah konsep yang memiliki kaitan dengan nasionalisme. Bela negara dapat muncul karena rasa nasionalisme yang dimiliki oleh seseorang dan sah untuk dimiliki oleh siapa saja. Bahkan siswa dalam usia sekolah dasar sekalipun. Nasionalisme menurut (Mustari, 2011) merupakan sikap yang dimiliki oleh seseorang terhadap bangsa, bahasa, adat istiadat, udaya, dan juga sikap nasionalnya. Nasionalisme ini biasanya melihatkan suatu negara maupun etnis tertentu. Dengan adanya semangat nasionalisme, merupakan suatu bentuk yang meyakini bahwa apa yang ia miliki mencakup tenis, bahasa, adat, dan sebagainya merupakan sesuatu yang penting dan perlu untuk dilindungi dan juga dibela. Yang pada akhirnya hal ini berkaitan dengan upaya bela negara yang dimiliki oleh seorang.

Siswa pada usia sekolah dasar merupakan siswa yang memiliki kemampuan dalam menginterpretasikan mengenai fenomena sosial melalui cara mereka sendiri, sehingga dalam hal ini pendampingan masih diperlukan oleh guru maupun orang tua untuk mencegah interpretasi yang menyimpang jauh dan salah (Russell III, 2012). Hal ini juga berlaku bagi bagaimana cara siswa sekolah dasar memahami mengenai konsep bela negara dan fungsi mereka sebagai warga negara. Pendidikan dan cara mendidik yang dilakukan harus benar-benar disesuaikan dan dipahami kondisinya. Karena, apa yang diajarkan pada jenjang sekolah dasar akan menjadi dasar bagi pendidikan, pengetahuan, dan pemahaman siswa akan sesuatu hingga ke jenjang pendidikan yang selanjutnya.

Pada penerapannya Pendidikan Kewarganegaraan mempunyai pancasila dimana itu sebagai dasar Negara yang didalamnya mempunyai nilai dan makna yang terkandung sebagai pedoman kehidupan. Penerapannya bila dilakukan kapan saja dan dimana saja serta harus diajarkan di semua jenjang pendidikan agar sejalan dengan nilai dan norma yang berlaku untuk kehidupan sehari-hari menurut (Angel, 2021) Pendidikan Kewarganegaraan memiliki fungsi sebagai pemandu dalam menentukan bagaimana pola pikir siswa terhadap upaya bela negara yang mereka lakukan. Hal yang benar adalah tentu berkaitan dengan nasionalisme tentang rasa cinta tanah air. Termasuk didalamnya memahami bagaimana Indonesia adalah negara yang plural dan memiliki multicultural di dalamnya.

Disinilah peran Pendidikan Kewarganegaraan mengambil alih. Dimana Pendidikan Kewarganegaraan dapat memiliki fungsi pengetahuan dan sikap sebagai media penguatan multikulturalisme di Indonesia; kemudian Pendidikan Kewarganegaraan dapat menjadi inovasi dan model pembelajaran yang menyenangkan dalam mengajarkan siswa sekolah dasar mengenai bangsa dan negara Indonesia; dan terakhir, Pendidikan Kewarganegaraan memiliki makna filosofis sebagai landasan kekuatan pengikat dalam pembentukan mentalitas pluralisme multikultural dalam rangka mewujudkan tujuan nasional dan modernisasi bangsa tanpa meninggalkan kearifan lokal (Wibowo \& Wahono, 2017). Dimana apabila hal-hal ini diterapkan bagi siswa sekolah dasar dengan cara dan metode yang tepat, maka dasar bagi nilai bela negara yang akan dimiliki siswa akan menjadi kuat pula.

Pada hal ini metode penerapan tentu saja terbagi menjadi beberapa bagian. Namun pada dasarnya, metode yang tepat haruslah tetap melibatkan unsur kognitif untuk memberikan pengetahuan bagi siswa sekolah dasar misalnya dengan pengajaran di kelas, diskusi, bercerita, penanaman nilai dan moral, dan sebagainya (Prihandoko et al., 2017); dapat pula dilakukan dengan afektif guna memberikan pemahaman dengan pendekatan khusus melalui memberikan contoh sikap dan perilaku, pendekatan emosional, dan lainlain (Keegan, 2021); atau dapat pula menggabungkan pendekatan kognitif dan afektif melalui sebuah inovasi yang melibatkan teknologi dan cara-cara menyenangkan dalam mempelajari Pendidikan Kewarganegaraan 
4687 Penerapan Pendidikan Kewarganegaraan sebagai Penguat Sikap Bela Negara Bagi Siswa Sekolah Dasar - Dini Angraeni Dewi, Yayang Furi, Angel Dwi Septiaingrum, Vioreza Dwi Yunianti DOI: https://doi.org/10.31004/edukatif.v3i6.1550

(Hidayat et al., 2020) . Jadi dengan demikian hal-hal tersebut diharapkan dapat mempermudah siswa sekolah dasar selama pembelajaran pendidikan kewarganegaraan berlangsung. Penerapan pendidikan kewarganegaraan juga dapat berproses dengan efektif sehingga bisa mencapai tujuan pembelajaran.

\section{KESIMPULAN}

Dari uraian-uraian diatas yang menjelaskan tentang Pendidikan Kewargananegaraan dapat ditarik kesimpulan bahwa pendidikan tersebut merupakan sebuah tuntutan untuk tercapainya tujuan tentang hak dan juga kewajiban warga Negara pada aspek pengetahuan, keterampilan, maupun nilai dan sikap. Maka dari itu, untuk menumbuhkan rasa nasionalisme serta upaya implementasi bela negara itu sendiri. Peran Pendidikan Kewarganegaraan dalam menentukan sikap bela negara yang dimiliki oleh siswa sekolah dasar dilakukan dengan membantu siswa dalam memahami mengenai nasionalisme yang merupakan rasa mencintai negara, serta paham akan multikulturalisme untuk memahami bahwa Indonesia adalah negara yang plural dan tidak terdiri dari satu jenis bahasa, suku, etnis, agama, dan lain-lain saja. Selain itu, Pendidikan Kewarganegaraan pun memiliki peran kontrol dalam membatasi mengenai apa dan bagaimana yang perlu diketahui siswa mengenai bangsa dan negara pada umur tersebut. cara yang dapat dilakukan untuk menerapkan upaya bela negara ini adalah dengan cara seperti kognitif, afektif, dan gabungan keduanya menggunakan inovasi dan teknologi. Saat ini di Indonesia sendiri memeiliki banyak masalah pengimplementasian terhadap Pendidikan kewarganegaraan yang dipengaruhi oleh banyak hal. Untuk itu lembaga pendidikan pun harus ikut serta aktif untuk menangani hal tersebut agar pada penerapannya tujuan Pendidikan Kewarganegaraan akan tercapai secara penuh tanpa adanya doktrin khusus yang dapat menghambat pola pikir kritis siswa.

\section{DAFTAR PUSTAKA}

Harmanto, Listyaningsih, \& Wijaya, R. (2017). Characteristics of competence and civic education materials curriculum in primary school in Indonesia. The 2nd International Joint Conference on Science and Technology (IJCST), 953(1). https://doi.org/10.1088/1742-6596/953/1/012150

Hidayat, H., Mulyani, H., Nurhasanah, S. D., Khairunnisa, W., \& Sholihah, Z. (2020). Peranan Teknologi Dan Media Pembelajaran Bagi Siswa Sekolah Dasar Di Dalam Pembelajaran Pendidikan Kewarganegaraan. Jurnal Pendidikan Kewarganegaraan Undiksha, 8(2), 35-46. https://ejournal.undiksha.ac.id/index.php/JJPP

Iswandi, D. (2019). Dimensi Kurikuler Pendidikan Kewarganegaraan Sebagai Program Pendidikan di Sekolah Dasar Kelas Rendah. Jurnal Civicus, 19(1), 1-8.

Keegan, P. (2021). Critical affective civic literacy: A framework for attending to political emotion in the social studies classroom. The Journal of Social Studies Research, 45(January), 15-24.

Komara, E. (2017). Curriculum and civic education teaching in Indonesia. EDUCARE: International Journal for Educational Studies, 10(1), 23-32. www.mindamas-journals.com/index.php/educare

Kurniawan, M. I. (2013). Integrasi Pendidikan Karakter Ke Dalam Pembelajaran Kewarganegaraan Di Sekolah Dasar. Jurnal Pemikiran Dan Pengembangan Sekolah Dasar (JP2SD), 1(1), 37. https://doi.org/10.22219/jp2sd.v1i1.1528

Magdalena, I., Haq, A. S., \& Ramdhan, F. (2020). Pembelajaran Pendidikan Kewarganegaraan Di Sekolah Dasar Negri Bojong 3 Pinang. Jurnal Pendidikan Dan Sains, 2(3), 418-430. https://ejournal.stitpn.ac.id/index.php/bintang

Mustari. M. (2011).. Nilai Karakter. Yogyakarta: LaksBang PRESSindo

Nurdin, E. S. (2015). The Policies on Civic Education in Developing National Character in Indonesia. International Education Studies, 8(8), 199-209. https://doi.org/10.5539/ies.v8n8p199

Prihandoko, Y., Slamet, S. Y., \& Winarno. (2017). Pendekatan Cognitive Moral Sebagai Kerangka 
4688 Penerapan Pendidikan Kewarganegaraan sebagai Penguat Sikap Bela Negara Bagi Siswa Sekolah Dasar - Dini Angraeni Dewi, Yayang Furi, Angel Dwi Septiaingrum, Vioreza Dwi Yunianti DOI: https://doi.org/10.31004/edukatif.v3i6.1550

Pengembangan Bahan Ajar Ppkn Di Sekolah Dasar. Jurnal Kependidikan, 1(2), 200-2013.

Rambey, A. (2020). Kasus Kekerasan yang Dipicu Masalah Keberagaman di Indonesia. Kompas. https://www.kompas.com/skola/read/2020/02/06/190000569/kasus-kekerasan-yang-dipicu-masalahkeberagaman-di-indonesia?page=all

Russell III, W. B. (2012). Social Studies, the Lost Curriculum: A Research Study of Elementary Teachers and the Forces Impacting the Teaching of Social Studies. Curriculum and Teaching, 24(2), 75-86. https://doi.org/10.7459/ct/24.2.07

Septianingrum, D, Angel \& Dewi, A. Dini. (2020), Vol3.no1

Soepandji, K. W., \& Farid, M. (2018). Konsep Bela Negara Dalam Perspektif Ketahanan Nasional. Jurnal Hukum \& Pembangunan, 48(3), 436. https://doi.org/10.21143/jhp.vol48.no3.1741

Sugihartono, Fathiyah, K. N., Harahap, F., Agus, F., \& Rohmah, S. (2013). Psikologi Pendidikan. UNY Press

Sugiyono. (2010). Metode Penelitian Kuantitatif Kualitatif dan R n D; Penerbit CV Alvabeta, Bandung.

Sunarso. (2018). The Dynamics of Civic Education within the Schools in Indonesia : A Study of Educational Politics and Curriculum in Three Orders. Asia Future Conference 2018 Faculty of Social Sciences Yogyakarta State University.

Ulfa, N., Hidayah, Y., \& Halimah, L. (2020). The Formation of Nationalism through Education of Citizenship in Elementary School. Jurnal Pendidikan Dan Pembelajaran Dasar, 13(1), 65-83.

Umra, S. I. (2019). Penerapan Konsep Bela Negara, Nasionalisme Atau Militerisasi Warga Negara. Jurnal Lex Renaissance, 4(1), 164-178. https://doi.org/10.20885/jlr.vol4.iss1.art9

Wibowo, A. P., \& Wahono, M. (2017). Pendidikan Kewarganegaraan: usaha konkret memperkuat multikulturalisme di Indonesia. Jurnal Civics: Media Kajian Kewarganegaraan, 14(2), 196-205. https://doi.org/10.21831/civics.v14i2.16043 